\title{
RELIGIOUS AUTHORITY FOR A NEW, MEDIATISED WORLD
}

\section{MARTA KOLODZIEJSKA, ONLINE CATHOLIC \\ COMMUNITIES: COMMUNITY, AUTHORITY, \\ AND RELIGIOUS INDIVIDUALISATION}

Antoni Głowacki

University of Warsaw

The book opens with the description of an image comparing Saint Peter's Square in 2005 and 2013. In the photo from 2005, the people are simply standing, their backs turned towards the photographer. The image from 2013, while showing a similarly composed scene, shines in the glow of smartphone screens. Nearly all the visitors, not being satisfied with merely looking at what is before their own eyes, are photographing or filming what they see. This image, which is mentioned at the very beginning of Marta Kołodziejska's Online Catholic Communities: Community, Authority, and Religious Individualisation, sets the scene. The author describes a world in which experience (including religious experience) is becoming increasingly mediatised. Even personal, immediate experience is transformed by the introduction of new media, changing our relationship with the world around us. Furthermore, due to the proliferation of personalised digital devices, the division between online and offline worlds has stopped making sense; these realities, which are no longer distinct (if they ever were), constantly merge.

In Online Catholic Communities, Kołodziejska describes how religious communities function in this highly digital modern context. She presents 
Catholic Internet discussion boards as an example of a new type of religious medium, which has emerged in step with the expansion of the Internet. Her work marries detailed description of a very specific research subject with broader reflection on the transformation of religion in today's world. In an analysis well-grounded in both theoretical reflection and empirical evidence, she investigates Internet forums in the context of the individualisation of religion, its mediatisation, and transformations of religious authority. She argues that Catholic discussion boards, which are based on sharing religious knowledge and its interpretations, allow for the emergence of both grassroots religious experts and new types of communication communities within the Church.

Adopting Susan Herring's approach of computer-mediated discourse analysis (CMDA), Kołodziejska frames her research questions in a particular way. First, she shifts attention from communities defined as static objects towards a more processual approach, which allows for a more nuanced analysis. Thus, it is not enough to ask, "Is this group a community?" It should rather be asked at what level a group constitutes a community. Furthermore, she identifies the construction of authority as an important part of the process of community building. Consequently, her main research questions could be summarised as follows: (1) how is religious authority constructed on forums?; (2) what levels of community building can be identified on forums?; and (3) how can these specific types of communities be placed in the broader context of modern religion, especially in regard to its individualisation?

Kołodziejska's analysis is based on the study of three Polish-language Catholic Internet message boards. The study was conducted using qualitative research methods - namely, discourse analysis supplemented with online questionnaires and personal interviews with the most active users. Kołodziejska followed debates in chosen threads, identifying moments of conflict and the exercise of authority.

However, before she proceeds to answer her research questions, she offers a comprehensive overview of the state of religion today, as well as the theoretical current in which she works. She begins these introductory remarks by discussing the development of sociological reflection on the transformation of religion and religiosity, focusing primarily on the theory of secularisation in Karel Dobbelaere's version. For Kołodziejska, the main factor driving the transformation of religious communities and religious authority is individualisation. By this she means both the pluralisation of religious options (the proliferation of religious denominations and 
the growing numbers of non-believers), as well as a more and more pronounced "pick and choose" tendency within the Church. While the process of religious individualisation appeared well before the development of the Internet, it has been further amplified by the mediatisation of religion and the growth of online religious content. This does not mean that the relationship between the Internet and traditional religious authority is straightforwardly adversarial. Digitalisation does not always result in institutions losing their power. On the contrary, religious authorities can (and do) use the Internet for their own goals. Kolodziejska shows at length the Church's responses to the Internet and its challenges. Nevertheless, while the relation between the Internet and authority may be more complex than has traditionally been thought, it can be said that the emergence of alternative religious communication channels is closely tied with the process of individualisation.

Having characterised modern religiosity as more and more individualised, Kołodziejska turns to online communities. She proposes analysing them as processes by describing specific observable dimensions of the community. This allows the features of online communities to be taken into account: the constant flux of members, with a more rapid rate of change than in offline communities, and the detachment from traditional boundaries of territory, kinship, and so forth. Furthermore, Kołodziejska describes them as communication communities, bound by practices rather than by values or structures. This processual and discursive concept of community is rooted in works by theorists such as Gerard Delanty, Zygmunt Bauman, and Michel Maffesoli. It is also compatible with contemporary thinking on the changes in the religious landscape, particularly with Heidi Campbell's notion of networked religion. The Internet, while offering space for a particular type of community (networked, malleable, individualistic, flexible), is not detached from offline structures, institutions, and communities. Using the Internet can either empower established communities or undermine them.

Following this grounding in sociological theory, the core of the book contains empirical data from Kołodziejska's own research. She analyses the exchanges on the micro level, often quoting extensive passages from online debates and investigating them in detail. The first part is devoted to the construction of authority online, the second to establishing the symbolic boundaries of online communities.

In the online Catholic forums studied by Kołodziejska, authority is based on religious knowledge, that is, on a person's proficiency in referring 
to sacred texts, to dogmas and tenets of the faith, or to religious institutions. This kind of knowledge-based authority is constructed and referenced in online exchanges. Religious knowledge is used in two main contexts: in giving advice or offering support in private matters (such as marital problems), and in more theoretical "source book" debates on dimensions of religious authority (the topics range from the meaning of specific Bible passages, through inter-religious dialogue, to incongruences between religious and scientific worldviews). Knowledge may be deployed for various (informational, persuasive, or confrontational) purposes.

These types of interactions result in the emergence of informal religious experts, who have demonstrated their knowledge of specific areas (such as Canon Law, Church teachings on a specific subject, or other religious denominations) and are recognised by other Internet users. Usually, the offline identities of the participants have no bearing on their authority online (especially since forums, in contrast to social media, are largely anonymous). While informal experts may be considered religious authorities independent of the official Church structure, they do not challenge it. A double-framing of authority occurs: top-down (ascribed) and bottom-up (achieved) authority exists concurrently.

In fact, due to their extensive knowledge, informal experts often serve as intermediaries between traditional sources of religious authority and other users. They interpret texts and offer guidance in understanding them. Informal religious experts cannot be considered a replacement for traditional authorities, but they perform a different role, vital for the religious self-empowerment of forum users. The online exchanges tracked by Kołodziejska served to further the democratisation and individualisation of religious knowledge in two main ways. First, informal experts share their knowledge, making it accessible to those who do not possess the skills or resources necessary to acquire it themselves. And second, while often acting as advocates of official Church positions, they have no control over the practical application of their advice, leading to the valorisation of personal (informed) choice. This is especially pertinent in regards to practical matters debated on forums, such as the use of contraceptives, and sexual morals in general. The informal experts generally cite relevant passages from the Canon Law and other Church documents, but they also emphasise the role of conscience in individual decisions.

Similarly, just as informal experts do not explicitly challenge the traditional hierarchy, online communities do not aim to replace offline ones (although dissatisfaction with the latter is often expressed). They supplement 
it by offering a different mode of religious communication. Kołodziejska devotes the final part of her work to showing the dimensions of community that can be observed on Catholic forums. Conforming with the model of communication communities, their boundaries are established discursively and symbolically. Symbolic boundaries are constructed online to differentiate between various user groups within forums, with the segmentation based mainly on the interpretation of sources of knowledge and underlying worldviews. These communities are not solid; alliances are constantly formed around certain interpretations of sources of knowledge, and they dissolve and reform when the topic of debate changes. In contrast to offline religious communities, which tend to be stable, their online counterparts are constantly in motion, detached from any kind of material anchoring. However, this does not mean that the symbolic boundaries are established chaotically: the same groupings appear again and again. On the forums studied by Kołodziejska, the division between the "(anti) religious rebels" (who view religion as subject to scientific understanding or rationality) and the "rigourists" (who understand religion as reality sui generis) systematically reappeared. In addition to these internal boundaries, the division between the forum as a whole and "ordinary Catholics" (as a negatively valorised group of reference) was established.

The book offers an insight into how the growing importance of the Internet as a medium for religious content affects the way in which religious authority is constructed, and what consequences it can have for religious communities. The digital nature of online communities amplifies processes that can also be observed in offline religious groups, making the former especially useful subjects for analysis. Throughout her work, Kołodziejska presents online Catholic forums as inherently individualistic. They are founded for the dissemination of knowledge to the benefit of individuals, not the community; they focus on the expression of opinions and emotions; their membership is based on people's personal decisions to join or leave.

Kołodziejska's work succeeds in no small part because of her well-chosen research material. Online Catholic discussion boards prove to be communities encapsulating important developments in mediatised religion. Yet the author's discourse on her own data occasionally feels defensive, as if she were excusing herself for studying discussion boards and not trendier topics, such as social media. This seems entirely unnecessary because, although these types of online communities may be losing popularity to other platforms, they still constitute an interesting research object, as the 
book attests. In fact, being closer to providing an "ideal type" of Internet interaction (anonymous, flexible, with no fixed boundaries, independent of offline constraints) than social media, discussion boards may provide better material for grasping the specificity of online communities.

The strength of Kołodziejska's book lies in her integration of its parts her ability to inscribe her own research object into the broad context of studies on the transformations of modern Catholicism. Detailed analysis is never detached from theoretical considerations. While the excerpts from forum debates are discussed at great detail, the book never strays too far from its main argument. The empirical data is always there for a reason: to illuminate the crucial processes of individualisation and mediatisation. At the same time, the data does not function merely as an example of familiar social phenomena. Kołodziejska's analysis sheds new light on the transformation of religion in today's world, mainly by presenting how authority is established in online religious communities. The image of communities based on the dissemination of knowledge and interpretation of religious sources (primary texts such as the Bible or the Catechism, but also recent statements of institutional authorities), and the ensuing democratisation of religious knowledge, are especially pertinent.

Working in a well-defined research tradition, Kołodziejska envisions her book as a building block in a broader project. As she puts it herself, its "general conclusions contribute to the body of research by adding another piece to the puzzle" (2018: 59). There is little doubt that it serves this purpose well. This writing strategy provides Online Catholic Communities: Community, Authority, and Religious Individualisation with a singular focus and decidedly advances its main argument.

At the same time, the "puzzle" approach positions the book not as a self-contained work but rather as an element of a greater whole, leaving some questions unanswered. First, by focusing on the inner workings of online communities, Kołodziejska largely leaves open the question of how Catholic forums fit in the larger picture of the religious experience of their users (although she did write more about the relationship between forums and offline communities in one of her earlier research articles (with Neumaier, 2016)). Second, it could be beneficial to situate religious online communities in the context of other modes of digital interaction. Kołodziejska does reference sociological theory on online communities, but there is little direct comparison between religious communities and those coming together in connection with other interests. For now, in regard to religious 
online communities, we cannot be sure which features result from their religiosity and which from their online character.

Some of the editorial decisions further amplify the need to consider Online Catholic Communities as part of a broader project rather than a standalone work. It should be read together with the author's research articles, which are cited throughout the book, as is especially visible when the discussion on methodology is relegated to a footnote, with reference to an outside source. While the decision not to repeat information presented previously is understandable, it may lead to the omission of important details.

In the end, Online Catholic Communities is a concise, focused work, pursuing a well-defined research objective. It supplies a deep analysis of a specific type of community, illuminating transformations of religion in the contemporary world. The author's investigation of how religious authority is established in the online context is especially novel and worth considering. And while she does not try to paint a comprehensive picture of networked, multi-site religion, her conclusions may have far-reaching application. If, as Campbell suggested, "the features of religion online closely mirror changes within the practice of religion in contemporary society" (2012: 65), then studying those processes in an online context might prove crucial for a scholarly understanding of the modern religious landscape. For this reason, Online Catholic Communities is surely a valuable addition to the study of digital religion, and religion in general; as such, it is vital reading for scholars in the field.

Bibliography:

/// Campbell H. 2012. "Understanding the Relationship between Religion Online and Offline in a Networked Society," Journal of the American Academy of Religion, vol. 80(1), pp. 64-93.

/// Kołodziejska M. 2018. Online Catholic Communities: Community, Authority, and Religious Individualisation, Routledge.

/// Kołodziejska M., Neumaier A. 2016. "Between Individualisation and Tradition: Transforming Religious Authority on German and Polish Christian Online Discussion Forums," Religion, vol. 47(2), pp. 228-255. 
/// Antoni Głowacki - PhD candidate at the Institute of Sociology, University of Warsaw. He completed his studies at MISH UW and EHESS in Paris. He specialises in sociology and anthropology of religion, and he has conducted research on Catholicism in Poland and France. His most recent publication is an article in the Qualitative Sociology Review ("To Each His Own Way to Live His Faith.' Models of Religiosity in Parisian Catholic Parish," vol. 15(1), 2019)

ORCID: https://orcid.org/0000-0001-9553-7238

Email: a.glowacki@is.uw.edu.pl 